\title{
Evaluating the potential risks and benefits of infant rotavirus vaccination in England
}

\author{
Andy Clark ${ }^{\mathrm{a}, *}$, Mark Jit ${ }^{\mathrm{b}, \mathrm{c}}$, Nick Andrews ${ }^{\mathrm{c}}$, Christina Atchison ${ }^{\mathrm{d}}$, \\ W. John Edmunds ${ }^{\mathrm{b}}$, Colin Sanderson ${ }^{\mathrm{a}}$ \\ a Department of Health Services Research and Policy, London School of Hygiene and Tropical Medicine, 15-17 Tavistock Place, London WC1H 9SH, UK \\ ${ }^{\mathrm{b}}$ Department of Infectious Disease Epidemiology, London School of Hygiene and Tropical Medicine, Keppel Street, London WC1E 7HT, UK \\ c Statistics Modelling and Economics Department, Health Protection Directorate, Public Health England, London NW9 5EQ, UK \\ ${ }^{\mathrm{d}}$ Department of Primary Care and Public Health, School of Public Health, Imperial College, London W6 8RP, UK
}

\section{A R T I C L E I N F O}

\section{Article history:}

Received 11 February 2014

Received in revised form 21 April 2014

Accepted 23 April 2014

Available online 9 May 2014

\section{Keywords:}

Rotavirus

Vaccination

Intussusception

Risk-benefit analysis

\begin{abstract}
A B S T R A C T
Rotarix $^{\circledR}$, a vaccine for the prevention of gastroenteritis in young children, was introduced in England in July 2013. At around this time, an elevated risk of intussusception (a cause of bowel obstruction) was reported among infants vaccinated in Australia and the USA. A risk-benefit analysis compared potential vaccine-related risks (additional intussusception admissions and deaths) with estimated vaccine benefits (prevented rotavirus general practitioner visits, emergency visits, admissions and deaths) in the 2012 birth cohort. Detailed data from England included the incidence of intussusception events aged $<2$ years by week of age, the coverage of vaccination aged $<2$ years by week of age, and the incidence of rotavirus gastroenteritis (RVGE) events aged $<5$ years by week of age. Recent estimates of vaccine-related risk from Australia were applied during the 1-21 day period after the first and second dose of vaccination. Rotarix ${ }^{\circledR}$ is estimated to cause one additional intussusception admission in every 18,551 vaccinated English infants (5th and 95th percentiles, 6728-93,952), equivalent to 35 (7-98) additional intussusception admissions each year. The vaccine is estimated to prevent three rotavirus deaths, 13,000 rotavirus admissions, 27,000 rotavirus emergency visits and 74,000 rotavirus GP consultations in children aged $<5$ years, and lead to annual savings of over $£ 11$ million, each year. We estimate 375 (136-1900) fewer RVGE admissions for every additional intussusception admission, and 88 (18-852) fewer RVGE deaths for every additional intussusception death. The estimated benefits of Rotarix ${ }^{\circledR}$ vaccination would greatly exceed the potential risk in England.
\end{abstract}

(c) 2014 Published by Elsevier Ltd.

\section{Introduction}

Rotavirus is a leading cause of childhood diarrhoea in England. Although less than five children are estimated to die from rotavirus gastroenteritis (RVGE) each year [1], it is a common and painful illness and causes anxiety for parents. RVGE also represents a significant economic burden; one in seven English newborns will require a visit to their general practitioner (GP) before their 5th birthday, one in 22 will visit Accident and Emergency (A\&E) and one in 45 will be admitted to hospital. The estimated cost to the English National Health Service (NHS) is over ten million pounds annually [2].

Rotarix $^{\circledR}$ (GlaxoSmithKline), a vaccine for the prevention of severe RVGE in young children, was introduced in England in July

\footnotetext{
* Corresponding author at: London School of Hygiene and Tropical Medicine, 1517 Tavistock Place, London WC1H 9SH, UK.

E-mail address: andrew.clark@lshtm.ac.uk (A. Clark).
}

2013 [3]. The vaccine is administered orally, and is given in two doses at two and three months of age. The decision to introduce Rotarix $^{\circledR}$ was made by the Department of Health in November 2012 after it became possible to procure the vaccine at a cost-effective price [4]. The Joint Committee on Vaccination and Immunisation (JCVI) had previously reviewed studies showing that Rotarix ${ }^{\circledR}$ would not be cost-effective unless priced at $£ 19$ per dose ( $£ 38$ per course) or lower [5,6]. At this price each year of full health gained by vaccination would cost the Government $£ 30,000$, the upper limit accepted by the National Institute for Health and Care Excellence (NICE) [7].

A randomised controlled trial of Rotarix ${ }^{\circledR}$ in six European countries reported vaccine efficacy of $90 \%$ against severe RVGE [8] and several high income countries, including Finland, Australia and the USA, have now introduced the vaccine with impressive declines in childhood rates of gastroenteritis [9]. There have however been concerns about the safety of rotavirus vaccines; the first rotavirus vaccine, RotaShield ${ }^{\circledR}$, was withdrawn from the market 
after an association was found that was consistent with it causing intussusception, a rare bowel disorder, in one in every 4670 to 9474 infants vaccinated in the USA [10]. Intussusception, when the bowel telescopes into itself, is the most common cause of bowel obstruction in young infants. Large safety trials of both new vaccines, Rotarix ${ }^{\circledR}$ and Rotateq ${ }^{\circledR}$ (Merck) were able to exclude the level of risk associated with $\operatorname{RotaShield~}^{\circledR}[11,12]$, but were not powered to exclude a lower level of risk. The level of risk that may turn out to be associated with Rotarix ${ }^{\circledR}$ in England is difficult to predict. However recent post-licensure data from two other high income settings, the USA and Australia, indicates a risk of one vaccine-related intussusception case in every 20,000 vaccinated infants [13]. This overall estimate is not directly comparable to the risk reported for RotaShield ${ }^{\circledR}$ because the new vaccines have been administered within age restrictions designed to avoid the peak age of intussusception.

If left untreated, intussusception is a fatal condition. However, in England, where most children have access to timely health care, fewer than $0.5 \%$ of cases are estimated to die, and most cases will have an uneventful recovery following enema reduction or surgery [14]. That Rotarix ${ }^{\circledR}$ continues to be used in all settings where an elevated intussusception risk has been detected (USA, Australia, Mexico, Brazil) implies that the benefits are considered to greatly outweigh this risk [13]. The World Health Organisation (WHO) has taken a similar position by recommending the global use of rotavirus vaccines despite their small known risk of intussusception, and has further recommended the removal of age restrictions in countries with delayed vaccination and high RVGE mortality, so that more children can receive the benefits of the vaccine $[15,16]$. These age restrictions are designed to ensure the vaccine is administered before the peak age of intussusception. In England, where vaccination is timely and RVGE mortality is low, health practitioners have been given clear advice to adhere to these age restrictions (first dose of Rotarix ${ }^{\circledR}$ given no later than 15 weeks and second dose of Rotarix ${ }^{\circledR}$ no later than 24 weeks) [4].

In England, the potential risk of vaccine-related intussusception is unlikely to become clear until at least 18 months after Rotarix ${ }^{\circledR}$ is introduced when the expected number of cases in the absence of a risk would be about two in the week after the first dose and five cases in the week after the second dose. In the interim, we aim to estimate the potential burden of vaccine-related intussusceptions each year, and try to balance this against the estimated health benefits of the vaccine. The aim of this analysis is not to alarm parents and health professionals about the, as yet unknown, risk of intussusception in England; rather we aim to help put the potential risk in context, so that both parents and policy makers can make an informed judgement about Rotarix ${ }^{\circledR}$ vaccination.

\section{Methods}

An Excel-based [17] cohort model with a finely disaggregated age structure (weekly to age one year, and monthly to age five years) was used to estimate the risks and benefits of Rotarix ${ }^{\circledR}$ vaccination in England. All parameter values, and uncertainty ranges are listed in Table 1.

\subsection{Estimated risks of Rotarix ${ }^{\circledR}$ (additional intussusception events)}

Previously described methods [15] were adapted to account for the two periods of risk (1-7 days and 8-21 days) following both the first and second dose. For each dose, the number of vaccine-related intussusception cases was calculated as follows:

$$
\begin{aligned}
& P_{Y} \times\left(C_{w}-C_{w-1}\right) \\
& \times \\
& {\left[I_{w} \times\left(\mathrm{RR}_{1-7}-1\right)\right.} \\
& + \\
& I_{w+1} \times\left(\mathrm{RR}_{8-21}-1\right) \\
& + \\
& \left.I_{w+2} \times\left(\mathrm{RR}_{8-21}-1\right)\right]
\end{aligned}
$$

number of new doses given in week of age

incidence of vaccine-related intussusception cases in 1-7 day risk period

incidence of vaccine-related intussusception cases in 8-14 day risk period

incidence of vaccine-related intussusception cases in 15-21 day risk period

where $P_{Y}$, mid-year population for single year of age (i.e. either $<12 \mathrm{~m}$ or $12-23 \mathrm{~m}$ population); $C_{w}$, cumulative coverage estimate for the week of age; $C_{w-1}$, cumulative coverage estimate for the week preceding the current week of age; $I_{w}$, background incidence of intussusception in week 1 after vaccination (1-7 days); $I_{w+1}$, background incidence of intussusception in week 2 after vaccination (8-14 days); $I_{w+2}$, background incidence of intussusception in week 3 after vaccination (15-21 days); $\mathrm{RR}_{1-7}$, relative risk of vaccine-related intussusception versus background intussusception during the 1-7 day period after vaccination; $R_{8-21}$, relative risk of vaccine-related intussusception versus background intussusception during the 8-21 day period after vaccination.

Mid-2012 population estimates for England were 696,400 (<12 months) and 684,000 (12-23 months) [18].

Vaccination coverage of DTP3 was estimated to be $94.7 \%$ by age 12 months and $96.4 \%$ at 24 months in England during the last quarter of 2012 [19]. Coverage of DTP1 and DTP2 (proxies for coverage of Rotarix ${ }^{\circledR}$ dose 1 and 2 ) are not routinely reported. We therefore applied a $2 \%$ drop-out rate between the 1 st (99\%) and 3rd (97\%) primary dose, as reported by WHO-UNICEF for the United Kingdom in 2012 [20], to give DTP1 coverage of $98.4 \%(99 / 97 \times 96.4 \%)$ at 24 months. We assumed DTP2 coverage would be $97.4 \%$ at 24 months, half-way between DTP1 and DTP3 coverage. Coverage at 12 months was estimated to be $97.8 \%$ for DTP1 and $96.3 \%$ for DTP2 by assuming one-third and two-thirds respectively, of the relative difference between 12 and 24 month coverage reported for DTP3.

We assumed Rotarix ${ }^{\circledR}$ would have the same delays in administration as the first two doses of DTP (Diphtheria-Tetanus-Pertussis). DTP1 and DTP2 timeliness was estimated by week of age for a sample of children $(n=37,046)$ born in the year 2010 from child health information systems covering 14 different regions of England (Avon, South Birmingham, Buckinghamshire, Chesterfield, Devon, Dorset, Dudley, Herefordshire, Kent, Manchester, Northampton, Stafford, Walsall, Warwickshire) [19]. Age restrictions were applied to the base case scenario; coverage was truncated at 15 weeks of age for dose one and 24 weeks of age for dose two (dose two coverage could not exceed dose one coverage).

The background age-specific incidence of intussusception in England was based on Hospital Episode Statistics (HES) for children aged $<2$ years, pooled for the 10.75 year period between April 2002 and December 2012 [21]. Incidence of intussusception was relatively stable in this age group over the period so numbers of cases in each week were divided by 10.75 to estimate weekly incidence in a single calendar year. A gamma distribution (mean 30.8, standard deviation 14.2 and shift -0.36) was fitted to the age distribution. The estimated annual incidence of intussusception was 28.1 (95\% CI: $24.1-32.3$ ) per 100,000 children aged $<12$ months, and 18.0 (95\% CI: $15.8-20.4$ ) per 100,000 children aged <2 years, based on mid-2008 populations of 667,568 and 1307,342 respectively. On average, each year there were 187 intussusception hospital admissions aged $<12$ months and 48 admissions aged $12-23$ months.

The risk of vaccine-related intussusception is not yet known for England, but is likely to be closer to the situation in the USA and 
Table 1

Parameters and probability distributions used for Monte Carlo simulations.

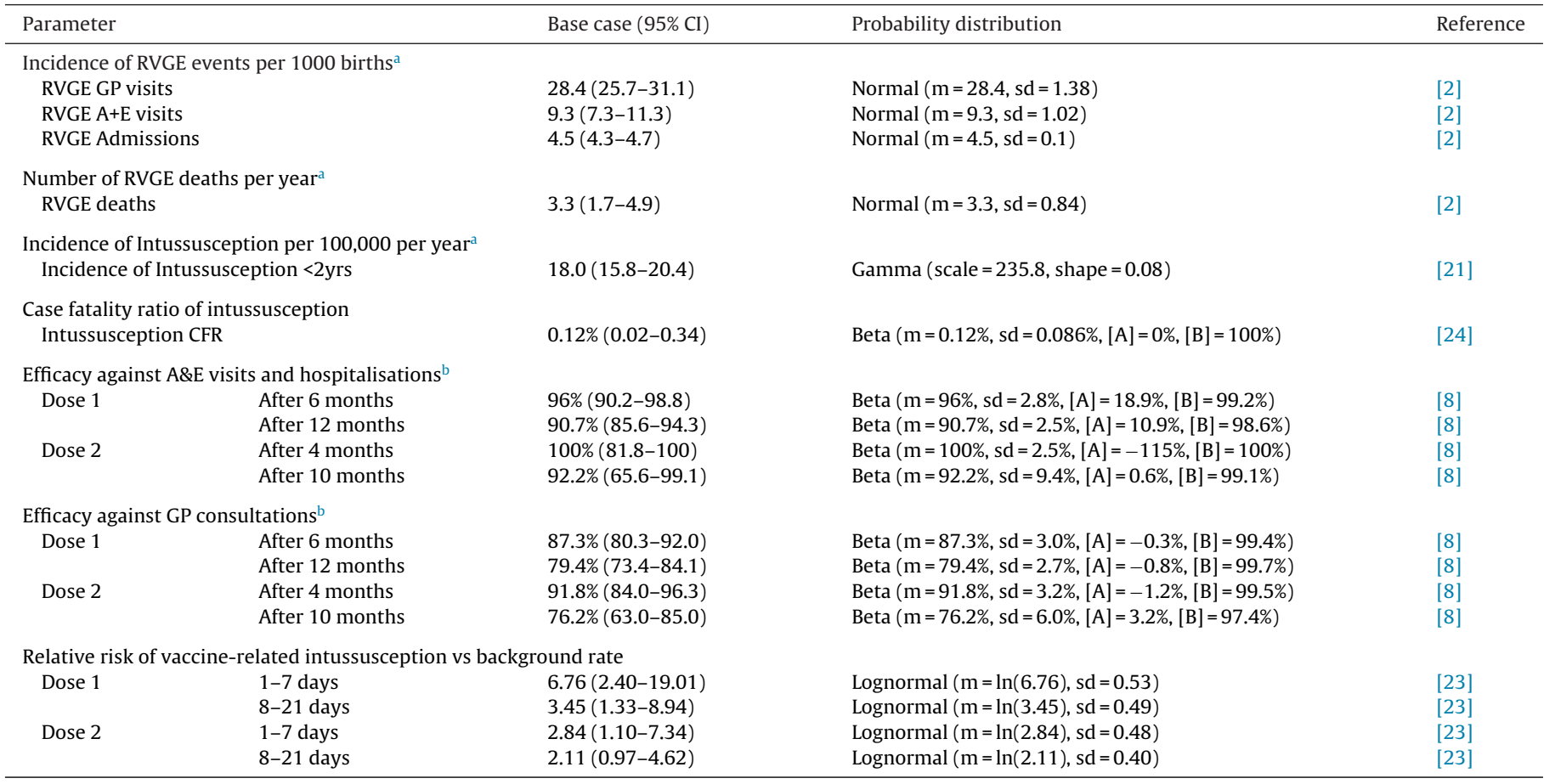

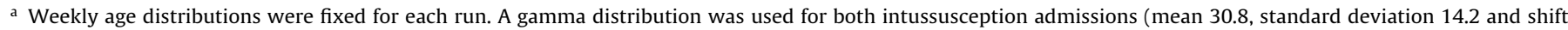
-0.36) and RVGE admissions (mean 70.7, standard deviation 36.6 and shift 8.26) based on 10.75 and 3 years respectively, of hospital episode statistics.

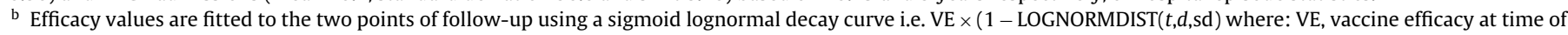
vaccination; $t$, time in weeks since vaccination; $d$, mean duration of protection, $s d=$ standard deviation duration of protection.

Australia, than in Mexico or Brazil. In the USA one additional case of vaccine-related intussusception has been reported for every 18,713 infants vaccinated based on 207,955 doses of Rotarix ${ }^{\circledR}$ monitored through the Vaccine Safety Datalink(VSD). Because very few infants are unvaccinated in this monitoring system, a rapid cycle analysis is used to establish whether the intussusception incidence exceeds a critical value, and confidence limits are not available [13]. The overall estimate of risk from Australia is very similar: one vaccinerelated intussusception in every 20,000 vaccinated infants (95\% CI: $9,000-53,000)$ based on a self-controlled case-series analysis [23]. To evaluate the potential risk of vaccine-related intussusception in England, estimates of relative risk (RR) are needed for the different periods of risk following each dose. The Australian estimates of RR were used for this analysis (Table 1).

We assumed a case fatality ratio (CFR) of $0.12 \%(95 \% \mathrm{CI}$ : $0.02-0.34 \%$ ) based on three intussusception deaths reported among 2588 cases identified in nine studies across seven European countries [24].

\subsection{Estimated benefits of Rotarix ${ }^{\circledR}$ (RVGE events prevented)}

For estimates of Rotarix ${ }^{\circledR}$ vaccine impact, RVGE events included GP consultations, visits to A\&E and admissions in children aged $<5$ years. In brief, the number of RVGE events in each week of age following Rotarix ${ }^{\circledR}$ vaccination was calculated as follows:

$\left.R_{w} \times\left(1-\left(\left(C_{2 w} \times E_{2 w}\right)+\left(C_{1 w}-C_{2 w}\right) \times E_{1 w}\right)\right)\right)$

where $R_{w}$, number of RVGE events in week of age; $E_{1 w}$, partial ( 1 dose) vaccine efficacy in week of age, adjusted for waning since vaccination; $E_{2 w}$, full ( 2 dose) vaccine efficacy in week of age, adjusted for waning since vaccination; $C_{1 w}$, coverage of dose one in week of age, adjusted for age restriction scenario; $C_{2 w}$, Coverage of dose two in week of age, adjusted for age restriction scenario.
The baseline number of RVGE events was updated to the year 2012 using a mid-year population of 3,393,400 (<5 yrs) in England [18]. Each of these outcomes was converted into a weekly age distribution (gamma distribution with mean 70.7, standard deviation 36.6, and zero shifted 8.26) fitted to 39,966 laboratory-confirmed rotavirus cases detected in England and Wales between January 2005 and December 2007 [25].

For vaccine efficacy after 1 and 2 doses, during year 1 and year 2 post-vaccination, we used results reported in a randomised controlled trial of Rotarix ${ }^{\circledR}$ in six European countries: Czech Republic $(n=299)$, Finland (2890), France (146), Germany (289), Italy (25), and Spain (345) [8]. A sigmoid (reverse S) shape curve was fitted to year one and year two efficacy to account for waning levels of protection with time post-vaccination. To estimate overall efficacy in each age slice, a decay matrix was used to account for the variation in age at vaccination and waning protection with time.

A dynamic transmission model [26] assuming 91\% coverage and realistic mixing patterns estimated that herd effects would account for only $3 \%$ of the total reduction in RVGE cases across all ages in England. Indirect effects were therefore excluded from this analysis.

Weekly coverage rates and age restrictions were applied to the base case scenario as described above.

\subsection{Risk benefit analysis}

10,000 probabilistic (Monte Carlo) simulations were run using the parameters and distributions defined in Table 1; each run reported the expected number of RVGE GP consultations, A\&E visits, admissions and deaths prevented, as well as the estimated number of intussusception admissions and deaths caused. In addition, the risk ratios (infants vaccinated per additional intussusception; admissions/deaths prevented per additional intussusception) were 


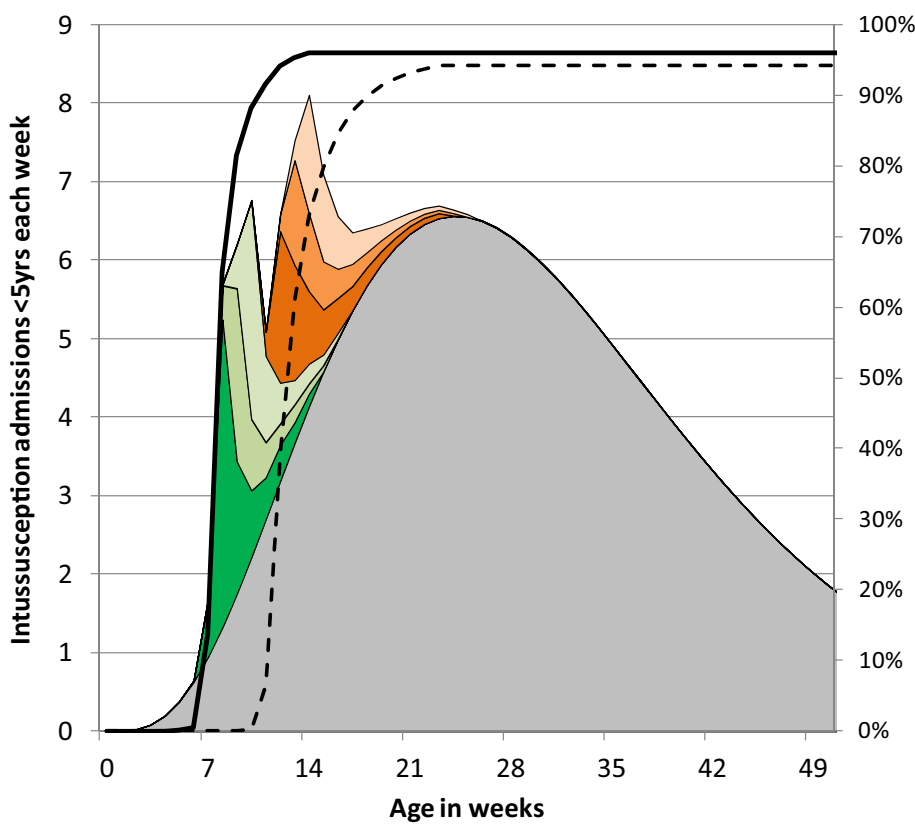
$100 \%$

90\% $\square$ Excess IS cases, 15-21 days after dose 2

80\% $\square$ Excess IS cases, 8-14 days after dose 2

$70 \%$

品 $\square$ Excess IS cases, 1-7 days after dose 2

$60 \%$

¿ $\square$ Excess IS cases, 15-21 days after dose 1

$50 \%$

음 $\square$ Excess IS cases, 8-14 days after dose 1

$\square$ Excess IS cases, 1-7 days after dose 1

$\square$ Intussusception cases without vaccination

-Dose 1 coverage

- - Dose 2 coverage

Fig. 1. Base case estimate of excess intussusception cases each year in England following introduction of Rotarix ${ }^{\circledR}$ vaccine.

generated for each simulation. The median, 5 th and 95 th percentile of the 10,000 runs was calculated for all outcomes of interest.

We also evaluated the potential risks and benefits of removing the age restriction in England. Because information about the relative risk of vaccine-related intussusceptions is based on infants vaccinated according to strict age restrictions ( $<15$ weeks for dose one, $<24$ weeks for dose two), we ran two possible variants of an unrestricted scenario: one assuming the same RR in all ages, and the second assuming a two-fold increase in RR after 15 weeks for dose one and after 24 weeks for dose two.

\section{Results}

\subsection{Estimated risks of Rotarix ${ }^{\circledR}$}

With strict adherence to recommended age restrictions, introduction of Rotarix ${ }^{\circledR}$ could potentially cause 35 (7-98) additional intussusception cases in children aged <5yrs in England each year (Fig. 1). Without vaccination around 248 intussusception admissions are expected each year in children aged <2 years; with Rotarix ${ }^{\circledR}$ this is estimated to increase by $14 \%$ to 284 . The number of excess cases associated with dose one and dose two was similar; dose two had a smaller relative risk but is administered when the background rate of intussusception is higher. The overall risk estimate is expected to be around one vaccine-related intussusception in every 18,551 vaccinated infants $(6728-93,952)$. The lower limit for the range of risk associated with RotaShield ${ }^{\circledR}$ vaccine in the USA was one in 10,000 infants; for Rotarix ${ }^{\circledR}$ in England, less than $15 \%$ of the 10,000 Monte Carlo runs were within this range (Fig. 2).

\subsection{Estimated benefits of Rotarix ${ }^{\circledR}$}

We estimate the introduction of Rotarix ${ }^{\circledR}$ could potentially prevent around 74,000 GP consultations, 27,000 A\&E visits, 13,000

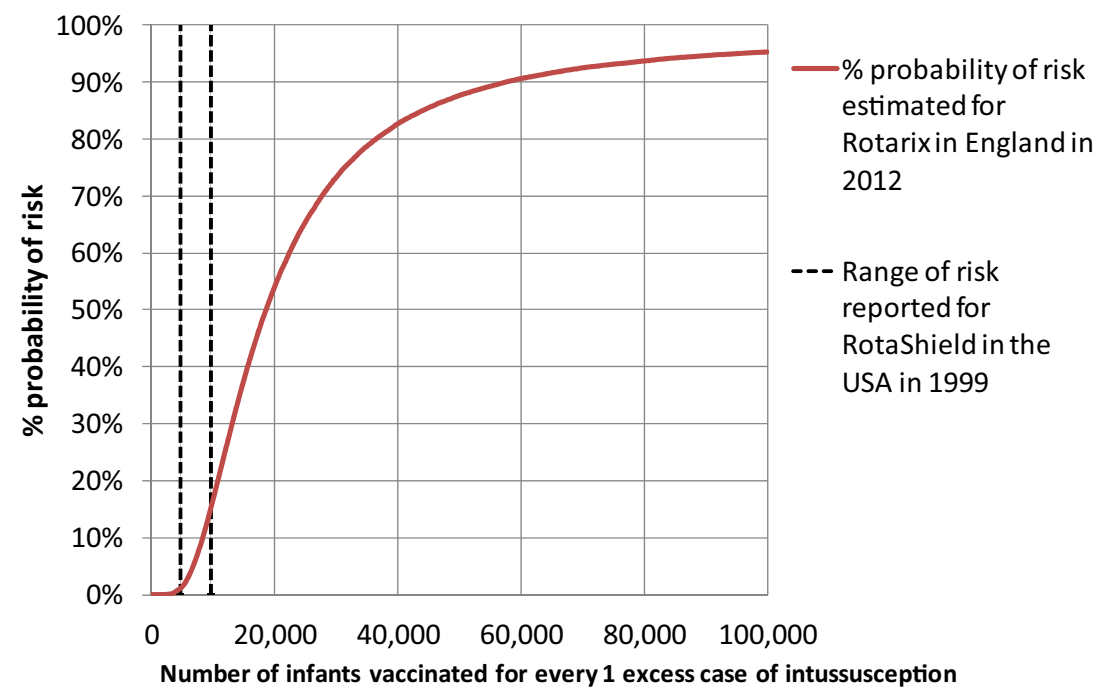

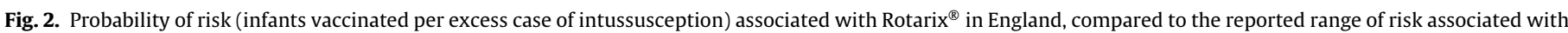
RotaShield ${ }^{\circledR}$ in the USA. 


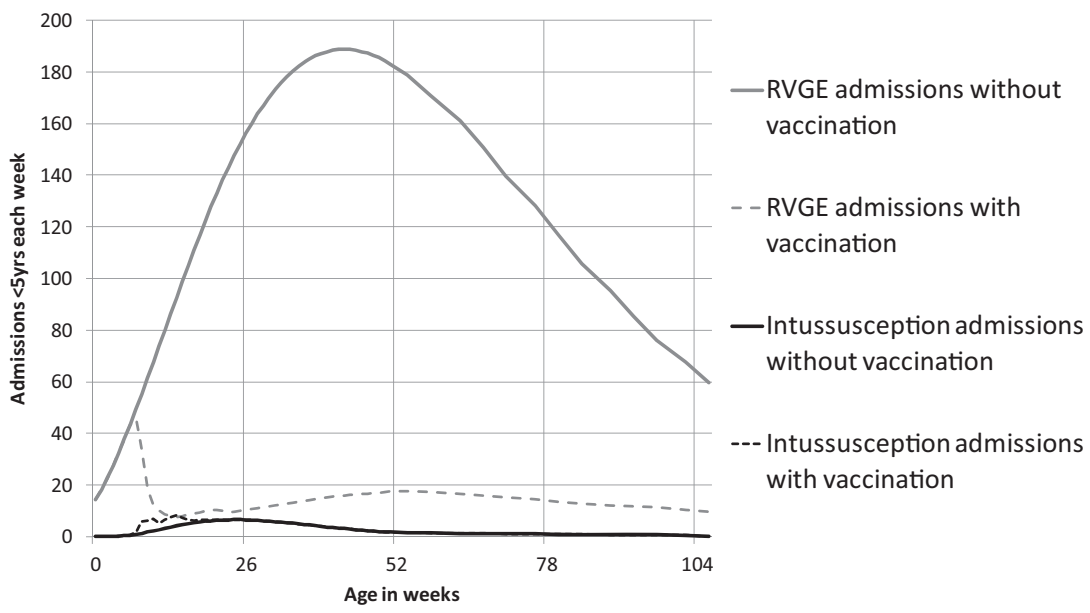

Fig. 3. Annual admissions per week (due to RVGE or intussusception), with and without Rotarix ${ }^{\circledR}$ vaccination in England.

Table 2

Estimated annual risks and benefits of Rotarix ${ }^{\circledR}$ introduction in England.

\begin{tabular}{|c|c|c|c|c|c|c|}
\hline & \multicolumn{2}{|c|}{ Infants within age window } & \multicolumn{2}{|c|}{ Infants outside age window } & & \\
\hline & \multirow[b]{2}{*}{ Median } & \multirow[b]{2}{*}{ 5th and 95th pc. } & \multicolumn{2}{|c|}{ Constant RR with age } & \multicolumn{2}{|c|}{ Two-fold RR outside window ${ }^{\mathrm{b}}$} \\
\hline & & & Median & 5th and 95th pc. & Median & 5th and 95th pc. \\
\hline $\begin{array}{l}\text { Number of infants vaccinated with } 2 \\
\text { doses }\end{array}$ & 656,457 & - & 21,836 & - & 21,836 & - \\
\hline \multicolumn{7}{|l|}{ Risks (Intussusception outcomes caused) } \\
\hline Admissions (Dose 1) & 19.2 & $(5.1,51.7)$ & 1.3 & $(0.4,3.5)$ & 2.4 & $(0.8,6.1)$ \\
\hline Admissions (Dose 2) & 16.2 & $(1.9,45.9)$ & 0.7 & $(0.1,1.9)$ & 5.2 & $(2.2,11.8)$ \\
\hline Admissions (Total) & 35.4 & $(7.0,97.6)$ & 2.0 & $(0.4,5.4)$ & 7.6 & $(3.1,17.9)$ \\
\hline Deaths & 0.03 & $(0.00,0.16)$ & 0.00 & $(0.00,0.01)$ & 0.01 & $(0.00,0.03)$ \\
\hline \multicolumn{7}{|l|}{ Benefits (RVGE outcomes prevented) } \\
\hline GP visits & 73,844 & $(66,422,81,351)$ & 1,701 & $(1497,1902)$ & 1701 & $(1497,1902)$ \\
\hline A\&E visits & 27,395 & $(22,220,32,743)$ & 678 & $(542,830)$ & 678 & $(542,830)$ \\
\hline Admissions & 13,276 & $(12,255,14,181)$ & 333 & $(277,368)$ & 333 & $(277,368)$ \\
\hline Deaths & 2.86 & $(1.66,4.10)$ & 0.07 & $(0.04,0.10)$ & 0.07 & $(0.04,0.10)$ \\
\hline \multicolumn{7}{|l|}{ Risk ratio $^{\mathrm{a}}$} \\
\hline $\mathrm{N}$ vaccinated per excess IS admission & 18,551 & $(6728,93,952)$ & 11,089 & $(4048,50,793)$ & 2,863 & $(1223,7,156)$ \\
\hline \multicolumn{7}{|l|}{ Risk-benefit ratio ${ }^{a}$} \\
\hline $\begin{array}{l}\text { RVGE admissions prevented per } \\
\text { excess IS admission }\end{array}$ & 375 & $(136,1900)$ & 169 & $(62,775)$ & 44 & $(19,109)$ \\
\hline $\begin{array}{l}\text { RVGE deaths prevented per excess IS } \\
\text { death }\end{array}$ & 88 & $(18,852)$ & 39 & $(8,358)$ & 9.6 & $(2.4,54)$ \\
\hline
\end{tabular}

a Risk ratios and risk-benefit ratios are based on the median from 10,000 Monte Carlo simulation runs; deriving them from the summary statistics may therefore give minor differences.

b Assumes dose 1 RR doubles after 15wks and dose 2 RR doubles after 24 wks.

admissions and 3 deaths in children aged $<5$ years, each year in England (Table 2). This is equivalent to savings of over $£ 11$ million per year based on previously published average costs of $£ 26$ per GP consultation, $£ 56$ per A\&E visit and $£ 612$ per admission [5].

\subsection{Risk-benefit of Rotarix ${ }^{\circledR}$}

During a single year with vaccination, we estimate that there would be 13,276 (12,255-14,181) fewer RVGE admissions and 35 (7-98) more intussusception admissions (Figs. 3 and 4). There would be 375 (136-1,900) fewer RVGE admissions for every additional vaccine-related intussusception admission. There would be 88 (18-852) fewer RVGE deaths for every additional intussusception death (Table 2 ).

\subsection{Risk-benefit of removing Rotarix ${ }^{\circledR}$ age restrictions}

Removing the age restriction would allow an additional 21,836 infants (3\% of the birth cohort) to be vaccinated, and the result would be 1701 fewer GP consultations, 678 fewer A\&E visits and

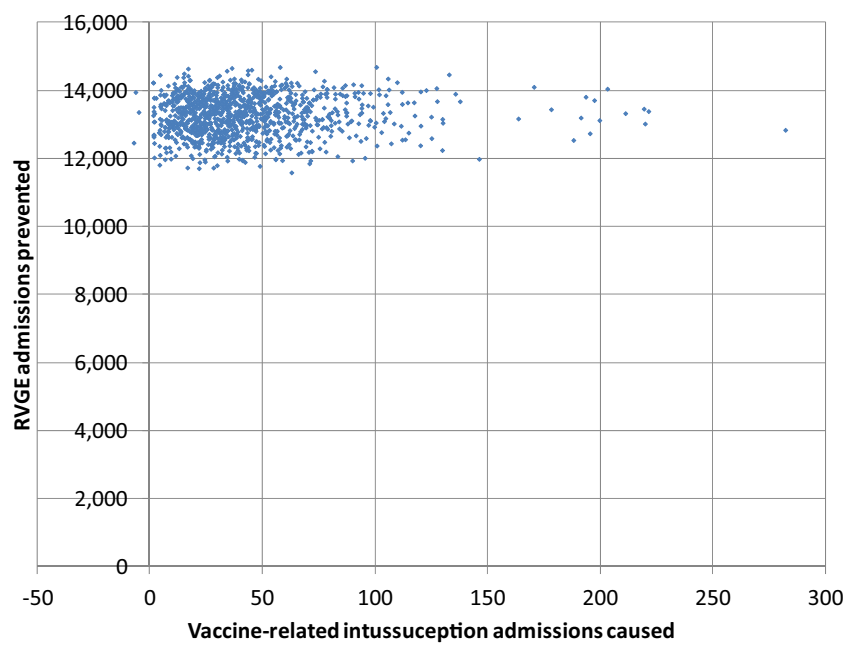

Fig. 4. Probabilistic sensitivity analysis to show annual intussusception admissions caused and RVGE admissions prevented by Rotarix ${ }^{\circledR}$ vaccination in England. 
333 fewer admissions each year. However, the risk among this subgroup would be around one additional intussusception in every 11,089 vaccinated infants and could be as high as one in every 2863 (with a two-fold increase in the RR outside of the age window). Among this subgroup 44-169 RVGE admissions could be prevented for every additional intussusception admission, and 10-39 RVGE deaths could be prevented for every additional intussusception death (Table 2).

\section{Discussion}

Our analysis suggests a potential risk of one vaccine-related intussusception in every 18,551 vaccinated infants, equivalent to 35 additional intussusception admissions each year. We estimate that Rotarix ${ }^{\circledR}$ would prevent around 74,000 GP consultations, 27,000 emergency visits and 13,000 admissions each year. This is equivalent to undiscounted savings of over $£ 11$ million annually. There would be 375 fewer RVGE admissions for every additional intussusception admission, and 88 fewer RVGE deaths for every additional intussusception death. Lifting the age restriction policy would allow an additional 21,836 infants to receive the benefits of Rotarix ${ }^{\circledR}$ vaccination, but the risk of intussusception among this subgroup would be higher (one in every 2863-11,089 vaccinated infants) and the risk-benefit ratio less favourable; in a pessimistic scenario (assuming a two-fold increase in the RR outside of the age window) for infants in this subgroup, only 44 RVGE admissions could be prevented for every one intussusception admission caused, and ten deaths prevented for every one intussusception death caused.

This is the first risk-benefit analysis of a Rotavirus vaccination programme in Europe and provides important reassurance for the recently introduced national immunisation programme. The analysis uses detailed information on the weekly age distribution of vaccination, intussusception and RVGE admissions in English infants and is supplemented by good quality information from other high-income settings. Indeed, one of the strengths of this analysis is that we are able to use the experience in other high income countries to inform the potential situation in England before local data become available. The recent Australian RR estimates were used; the overall risk ratios for the USA and Australia are similar but the Australian data cover a larger risk period (1-21 days) and include 95\% confidence intervals. Monte Carlo simulations were run to assess the implications of the uncertainty in the inputs used. In particular, the risk-benefit ratio for deaths is highly sensitive to the CFR used for cases of intussusception. It was necessary to pool the information from several European studies to obtain a reasonably robust sample size. We used a pooled estimate (3 deaths from 2588 cases) based on studies that were conducted in the United Kingdom and six other countries (Austria, Germany, Ireland, Russia, Spain and Turkey). This estimate could be biased in either direction; on the one hand the denominator is likely to include readmissions for the same infants, on the other hand, in at least one of the three deaths there were other complications likely to have contributed to the child's death [14]. The relatively low CFR is however consistent with recent estimates from the USA which have ranged from 0 to $0.2 \%$ between 2000 and 2009 [27]. The incidence rate for intussusception cases was based on primary diagnosis codes to avoid the potential inclusion of historical cases that were listed as a secondary diagnosis; this excluded around $6 \%$ of admissions $<2$ years. The figure of 187 primary diagnoses reported in children aged $<12$ months was similar to the 190 admissions aged $<12$ months reported by a separate prospective, active surveillance study in the year 2008/9 [22].

A recent risk-benefit analysis in the USA reported 1093 RVGE admissions prevented for every one additional intussusception admission and 77 RVGE deaths prevented for every additional intussusception death [28]. We estimated fewer RVGE admissions prevented per additional intussusception admission. However our analysis was based on risk evidence from Australia so accounted for risk associated with the second dose and also accounted for risk in the 8-21 day period after vaccination [28].

The estimated benefits of Rotarix ${ }^{\circledR}$ vaccination would greatly exceed the potential risk. However, national-level policy makers must take into consideration more than the 'greater good' of one vaccine in isolation. There are other criteria to be considered, and any suggestion that a vaccine might have adverse effects is a matter of great sensitivity, perhaps most importantly because of the potential consequences of negative press on the coverage of other vaccines which target more serious diseases such as meningitis. In England, concerns about the safety of whole-cell pertussis and MMR (measles mumps and rubella) vaccines have previously led to sharp falls in programme coverage [29]. The level of risk that prompted withdrawal of RotaShield ${ }^{\circledR}$ from the USA in 1999 was one in every $5000-10,000$ vaccinated infants. With over ten deaths and many hospital admissions due to rotavirus each year in the USA, some argued that the benefits of RotaShield ${ }^{\circledR}$ greatly exceeded this small-elevated risk [30]. Indeed the risk of serious adverse events associated with Ibuprofen, a common over-the-counter medication used to treat infants, is also estimated to be around one in every 10,000 [31]. The USA were the first to introduce RotaShield ${ }^{\circledR}$ so no post-licensure evidence existed elsewhere in the world at the time of its withdrawal. In contrast, a large amount of post-licensure evidence now exists for the second generation vaccines. The continued use of the second generation rotavirus vaccines in Australia, the USA and other countries where an elevated risk has been reported, demonstrates that a risk of one in every 20,000 is considered to be acceptable in those settings. A face-to-face survey among 260 parents in three US cities (Columbus, Denver, Knoxville) suggested an intussusception risk of one in every 2174 vaccinated infants would be acceptable to $90 \%$ of parents in the sample [32].

Both intussusception and severe RVGE are distressing illnesses, but in high-income settings both are highly treatable acute conditions of short duration. On the basis of mortality risk alone, Rotarix ${ }^{\circledR}$ would be strongly favoured; in England, one rotavirus death could be prevented every four months compared to one intussusception death caused every 20-30 years. This takes little account of the variation in mortality risk at the individual level but the risk of death from both outcomes is extremely rare in England. In contrast, episodes of RVGE are very common and can be distressing for both children and their parents. Finally, although the benefits of lifting the age restriction would still outweigh the risks, given wider considerations the balance may not be considered favourable enough to alter the current recommendation in England for strict adherence to the age restriction policy.

The risk of vaccine-related intussusception is yet to be determined in England and will not be available for some time. Meanwhile our analysis provides preliminary estimates of the potential risks and benefits of the vaccine. The potential harmful adverse effects of infant vaccination are understandably a highly sensitive topic for parents and healthcare workers. The aim of this analysis is not to create alarm about the, as yet undetected, level of risk in England. Intussusception cases will need to be monitored closely over the coming months. However, our analysis suggests the benefits of Rotarix ${ }^{\circledR}$ vaccination are likely to far exceed any potential risk.

\section{Funding}

AC and CS were commissioned by WHO's Initiative for Vaccine Research (Vaccine Schedules Initiative) to develop a multi-country model for evaluating the risks and benefits of Rotavirus vaccines. The analysis is based on the principles established during this work. 


\section{Contributions}

AC conceived the idea for the paper, developed the model, gathered the inputs, ran the analysis, drafted and revised the paper. MJ helped gather the inputs, updated a previous model to enable a comparison/validity check and provided edits and comments on the draft. NA (with Julia Stowe - see acknowledgements) organised the extraction and analysis of the intussusception and vaccination coverage datasets and provided edits and comments on the draft. CA provided the dataset on the age distribution of RVGE and provided edits and comments on the draft. JE provided comments on the draft. CS provided advice on data inputs and provided edits and comments on the draft.

\section{Acknowledgements}

We would like to thank Dr Julia Stowe for extracting the information on timeliness and the incidence of intussusception hospital admissions. We would also like to thank Dr Lamiya Samad for commenting on an earlier draft.

Conflicts of interest: AC, MJ, NA, CA and CS declare no conflicts of interest. JE's partner is employed by GSK.

\section{References}

[1] Jit M, Pebody R, Chen M, Andrews N, Edmunds WJ. Estimating the number of deaths with rotavirus as a cause in England and Wales. Hum Vaccin 2007;3(1):23-6.

[2] Harris JP, Jit M, Cooper D, Edmunds WJ. Evaluating rotavirus vaccination in England and Wales. Part I. Estimating the burden of disease. Vaccine 2007;25(20):3962-70.

[3] Joint letter from DH, PHE and NHS England (30th April 2013). Important changes to the national immunisation programme in 2013/14: introduction of rotavirus vaccination for babies at 2 and 3 months. Available at: https://www. gov.uk/government/uploads/system/uploads/attachment_data/file/193055/ 130429_Rotavirus_tripartite_letter_FINAL.pdf [accessed 07.08.13].

[4] The infant rotavirus vaccination programme - Q\&As for healthcare practitioners. Public Health England; 2013. Available at: https://www. gov.uk/government/uploads/system/uploads/attachment_data/file/224169/ Rotavirus_Q_and_As_for_healthcare_practitioners_v4_26_July_2013.pdf [accessed 7.08.13].

[5] Jit M, Edmunds WJ. Evaluating rotavirus vaccination in England and Wales. Part II. The potential cost-effectiveness of vaccination. Vaccine 2007;25(20):3971-9.

[6] Jit M, Mangen MJ, Melliez H, Yazdanpanah Y, Bilcke J, Salo H, Edmunds WJ, et al. An update to the cost-effectiveness of rotavirus vaccination: comparative analyses for five European countries and transferability in Europe. Vaccine 2010;28(47):7457-9.

[7] Measuring effectiveness and cost effectiveness: the QALY. National Institute for Health and Care Excellence (NICE). Available at: http://www.nice.org.uk/ newsroom/features/measuringeffectivenessandcosteffectivenesstheqaly.jsp [accessed 07.08.13], 2013.

[8] Vesikari T, Karvonen A, Prymula R, Schuster V, Tejador JC, Cohen R, et al. Efficacy of human rotavirus vaccine against rotavirus gastroenteritis during the first 2 years of life in European infants: randomised, double-blind controlled study. Lancet 2007;370(9601):1757-63.

[9] Tate JE, Cortese MM, Payne DC, Curns AT, Yen C, Esposito DH, et al. Uptake, impact, and effectiveness of rotavirus vaccination in the United States: review of the first 3 years of postlicensure data. Pediatr Infect Dis J 2011;30(Suppl. 1):S56-60.

[10] Murphy TV, Gargiullo PM, Massoudi MS, Nelson DB, Jumaan AO, Okoro CA, et al. Intussusception among infants given an oral rotavirus vaccine. New Engl J Med 2001;344(8):564-72.

[11] Ruiz-Palacios GM, Perez-Schael I, Velazquez FR, Abate H, Breuer T, Clemens SC, et al. Safety and efficacy of an attenuated vaccine against severe rotavirus gastroenteritis. New Engl J Med 2006;354(1):11-22.
[12] Vesikari T, Matson DO, Dennehy P, Van Damme P, Santosham M, Rodriguez Z, et al. Safety and efficacy of a pentavalent human-bovine (WC3) reassortant rotavirus vaccine. New Engl J Med 2006;354(1):23-33.

[13] Cortese M. Summary of intussusception risk and benefits of rotavirus vaccination in the United States. In: Centers for Disease Control and Prevention. ACIP Meeting. June 20, 2013. 2013. Available at: http://www.cdc.gov/ vaccines/acip/meetings/downloads/slides-jun-2013/06-Rotavirus-Cortese.pdf [accessed 19.08.13].

[14] Samad L, Marven S, El Bashir H, Sutcliffe AG, Cameron S, Lynn R, et al. Prospective surveillance study of the management of intussusception in UK and Irish infants. Br J Surg 2012;99(3):411-5.

[15] Patel MM, Clark AD, Sanderson CF, Tate J, Parashar UD. Removing the age restrictions for rotavirus vaccination: a benefit-risk modeling analysis. PLoS Med 2012;9(10):e1001330.

[16] Rotavirus vaccines, WHO position paper - January 2013. Weekly epidemiological record - 1st FEBRUARY 2013, vol. 88; 2013. p. 49-64. http://www.who.int/wer/2013/wer8805.pdf [accessed 07.08.13].

[17] Microsoft Excel. Redmond, WA, USA: Microsoft Corporation; 2007.

[18] Mid-2012 population estimates: England; estimated resident population by single year of age and sex. Office for National Statistics (Crown Copyright); 2013. Available at: http://www.ons.gov.uk/ons/rel/popestimate/population-estimates-for-england-and-wales/mid-2012/rft-mid2012-population-estimates-for-england-and-wales.zip [accessed 16.08.13].

[19] CarePlus Child Health Data for the 2010 birth cohort in 14 regions of England. Available at: http://mckesson.co.uk/child-health-0 [accessed 30th September 2013]. Extraction/analysis of DTP1, DTP2 and DTP3 coverage by week of age by Julia Stowe [Immunisation and Blood Safety Department, Public Health England], 2013.

[20] WHO UNICEF estimates time series for United Kingdom of Great Britain and Northern Ireland. WHO-UNICEF estimates of DTP1 coverage. Data as of 12.07.12. Available at: http://apps.who.int/immunization monitoring/globalsummary/estimates?c=GBR [accessed 19.08.13], 2012.

[21] Hospital Episode Statistics. Extraction/analysis of Intussuception admissions by week of age by Julia Stowe [Immunisation and Blood Safety Department, Public Health England]. Copyright (c) 2013, Re-used with the permission of the Health \& Social Care Information Centre. All rights reserved.

[22] Samad L, Cortina-Borja M, Bashir HE, Sutcliffe AG, Marven S, Cameron S et al. Intussusception incidence among infants in the UK and Republic of Ireland: a pre-rotavirus vaccine prospective surveillance study. Vaccine 2013;31(38):4098-102.

[23] Carlin JB, Macartney K, Lee KJ, Quinn HE, Buttery J, Lopert R, et al Intussusception risk and disease prevention associated with rotavirus vaccines in Australia's national immunisation program. Clin Infect Dis 2013;57(10):1427-34

[24] Jiang J, Jiang B, Parashar U, Nguyen T, Bines J, Patel MM. Childhood intussusception: a literature review. PLoS ONE 2013;8(7):e68482.

[25] Atchison CJ, Lopman BA, Harris CJ, Tam CC, Iturriza Gomara M, Gray JJ. Clinical laboratory practices for the detection of rotavirus in England and Wales: can surveillance based on routine laboratory testing data be used to evaluate the impact of vaccination? Eur Surv: Bulletin Europeen sur les maladies transmissibles=Eur Commun Dis Bull 2009;14(20):1-6.

[26] Atchison C, Lopman B, Edmunds WJ. Modelling the seasonality of rotavirus disease and the impact of vaccination in England and Wales. Vaccine 2010;28(18):3118-26

[27] Yen C, Tate JE, Steiner CA, Cortese MM, Patel MM, Parashar UD. Trends in intussusception hospitalizations among US infants before and after implementation of the rotavirus vaccination program, 2000-2009. J Infect Dis 2012;206(1):41-8

[28] Desai R, Cortese MM, Meltzer MI, Shankar M, Tate JE, Yen C, et al. Potential intussusception risk versus benefits of rotavirus vaccination in the United States. Pediatr Infect Dis J 2013;32(1):1-7

[29] Bauch CT, Bhattacharyya S. Evolutionary game theory and social learning can determine how vaccine scares unfold. PLoS Comput Biol 2012;8(4): e1002452.

[30] Weijer C. The future of research into rotavirus vaccine. BM] 2000;321(7260):525-6.

[31] Ibuprofen (c) NHS direct; 2013, http://www.nhsdirect.nhs.uk/Headache/ /media/SATFiles/MedsForPain-March2012/IbuprofenFactsheetMarch2012. ashx\#page5 [accessed 19.08.13].

[32] Sansom SL, Barker L, Corso PS, Brown C, Deuson R. Rotavirus vaccine and intussusception: how much risk will parents in the United States accept to obtain vaccine benefits? Am J Epidemiol 2001;154(11):1077-85 